\title{
AN INVITATION TO A NEW TRANSPORTATION MODE
}

\author{
Tyler C. Folsom \\ QUEST Integrated, Inc. \\ Kent, Washington, USA \\ tylerf@qi2.com
}

\begin{abstract}
The trends of Personal Rapid Transit (PRT) and Automated Highways are converging. The result may be a new transportation mode built around robotic vehicles. This paper outlines how technology can transform transportation, making it more convenient, safer, more sustainable and less subject to congestion. Such a system could utilize existing infrastructure, but split highway lanes in half with vehicles less than a meter wide. This paper presents lessons from several relevant vehicles that the author's research teams have worked on. It describes open source work in progress and invites participation from other researchers.
\end{abstract}

\section{KEY WORDS}

Transportation, Automotives, Vehicle telematics, Traffic telematics, fuel efficiency

\section{Introduction}

The last decade has seen a great deal of progress in autonomous vehicles. The transition to autonomy has generally been assumed to continue the car dependent transportation paradigm. Looking at the broader issues shows that it is possible to create a new transportation mode that blurs the distinctions between public and private transportation, bus, train, car and cycle. Such a system can have profound effects on both traffic injuries and energy consumption This paper begins with a review of two trends in transportation and suggests that they may converge. It then outlines one possible path. This is followed by summaries of vehicles that the author has participated in with lessons learned from each project. We then report on a current open source, open hardware prototype vehicle and invite collaboration on the project.

\section{Vehicle Systems}

\subsection{Personal Rapid Transit}

The notion of Personal Rapid Transit (PRT) dates from the 1960's and is illustrated in Figure 1. In 1988 the Advanced Transit Association defined a PRT [1] to consist of

1. Fully automated vehicles capable of operation without human drivers.

2. Vehicles captive to a reserved guideway.

3. Small vehicles available for exclusive use by an individual or a small group, typically 1 to 6 passengers, travelling together by choice and available 24 hours a day.

4. Small guideways that can be located above ground, at ground level or underground.

5. Vehicles able to use all guideways and stations on a fully coupled PRT network.

6. Direct origin to destination service, without a necessity to transfer or stop at intervening stations.

7. Service available on demand rather than on fixed schedules.

After more than 40 years, the number of operating PRT systems worldwide can be counted on the fingers of one hand. The theory is attractive, but some rethinking may be needed to get to a transportation system that can be as common worldwide as buses and subways.

There are two weakness in the PRT idea.

1. The need to construct new infrastructure. PRT proponents argue that the guideways would be light, requiring little space.

2. There is no good reason why the vehicles must be captive to the guideway. Vehicles captive to the guideway are called Single Mode (SM) and those capable of operating off guideway are called Dual Mode (DM). There has been considerable discussion of the merits of each approach.

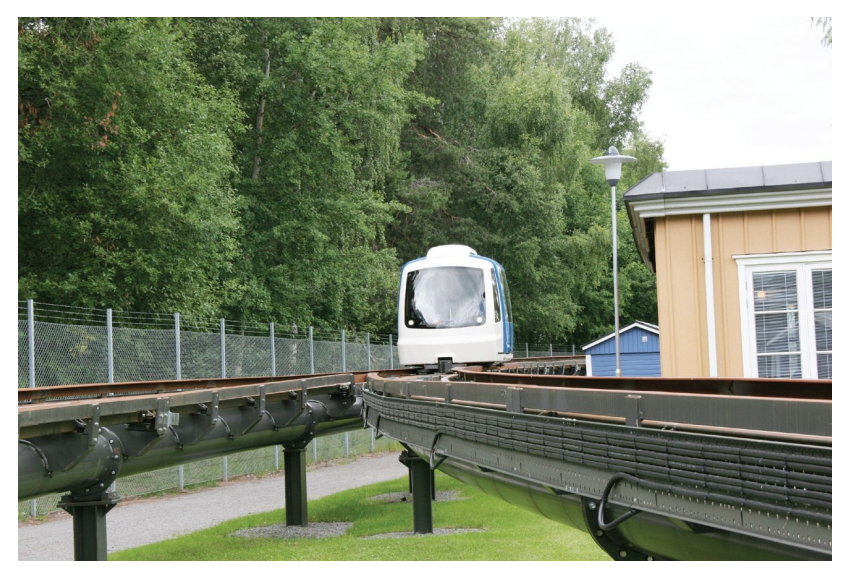

Figure 1. Vectrus PRT

\subsection{Platooning of Autonomous Vehicles}

The National Automated Highway System Consortium (NAHSC) has demonstrated a platoon of eight cars driving automatically with a 3 meter gap between vehicles as shown in Figure 2 [2, 3]. These produced a smooth ride and maintained the distance within $\pm 20 \mathrm{~cm}$. There is a 
trade-off between high positional accuracy and achieving a smooth ride [4]. At the same panel, S. Tsugawa presented similar platooning results for autonomous heavy trucks travelling with a $10 \mathrm{~m}$ gap. The ability of a truck to autonomously merge between two others was demonstrated in Japan. Work is underway in Europe to show that platoons of 8 instrumented vehicles could travel on highways with a driver operating the lead vehicle and the following vehicles operating autonomously [5].

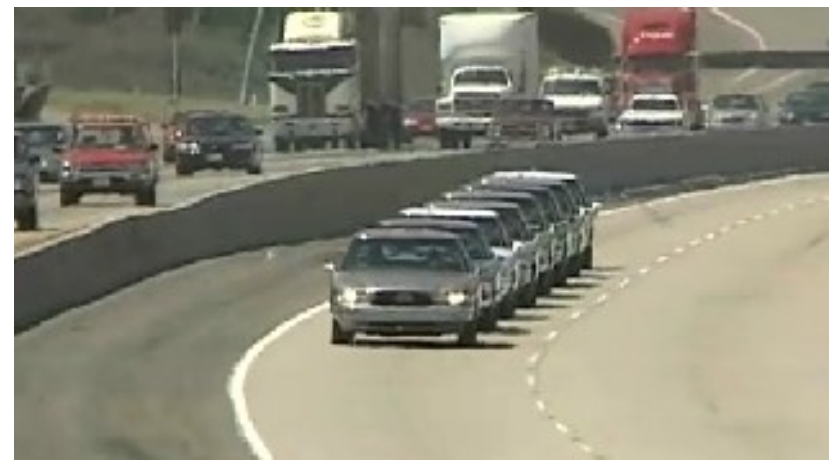

Figure 2: Platoon of eight vehicles

PRT is usually envisioned as a connector system within cities to supplement line haul transit systems. Automated highways are similar to the PRT concept for longer distances. The highway behaves as a PRT guideway using enhanced vehicles that are similar to what we drive today.

\subsection{Opportunity for a New Transportation Mode}

An autonomous vehicle travelling on a reserved guideway might represent public transit in the PRT design or it might be a private car in the automated highway design. Autonomous vehicles are a chance to blur the distinction between private cars and mass transit. A driverless vehicle might be public and be continuously reused after a passenger has finished with it. It might be a private vehicle and park itself remotely after the owner reaches her destination. The existence of such an option may make car ownership less important and make people willing to share their wheels in exchange for a lower level of financial commitment to transportation. At present, transportation accounts for $17.6 \%$ of the average U.S. family budget [6].

Autonomy may reduce the number of cars needed and it will certainly reduce the number of parking spaces required. A significant portion of the urban landscape is dedicated to parking.

An autonomous train began operation in Lille, France in 1983 and the autonomous Skytrain went into service in Vancouver, Canada in 1986. The Lille system is organized in two lines, includes 60 stations, extends over $45 \mathrm{~km}$ and carried 86 million passengers in 2007 [7]. Table 1 shows that these autonomous trains are much safer than Light Rail Transit (LRT) or Rapid Rail Transit
(RRT) [8]. It is reasonable to assume that autonomy can achieve a reduction in traffic accidents.

Table 1. Transit safety (Per million vehicle revenue $\mathrm{km}$ )

\begin{tabular}{|l|c|c|c|}
\hline System & Incidents & Injuries & Fatalities \\
\hline Lille & 2.8 & 0.0 & 0.0 \\
\hline Vancouver & 2.8 & 0.0 & 0.0 \\
\hline LRT systems & 39.3 & 30.5 & 0.1 \\
\hline RRT systems & 12.4 & 11.0 & 0.1 \\
\hline
\end{tabular}

When accidents become rare, an SUV offers little safety advantage over a motorcycle. This may lead to greater acceptance of light cars. The average American car weighs $1820 \mathrm{~kg}(4000 \mathrm{lb})$ [9], while the average American male weighs $86 \mathrm{~kg}(190 \mathrm{lb})$ [10]. If the car shrinks to $90 \mathrm{~kg}$, the total weight has decreased by a factor of 10. Energy required to overcome rolling resistance is proportional to mass, so energy needs decrease [11]. Platooning of vehicles with small gaps between them has been shown to cut fuel consumption by $20 \%$ [12]. Electric propulsion becomes more feasible in a lighter vehicle, which eliminates tail pipe emissions and reduces green house gas production.

\subsection{System Design}

If a new infrastructure is required, the transition to large scale PRT or autonomous cars is unlikely. If the new system can make use of the present infrastructure with only minor modifications, the transition is possible. We thus propose a system based on existing urban streets and highways.

The new transportation mode uses vehicles with a

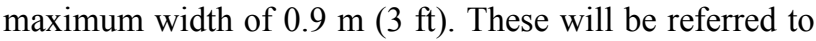
as pod cars. The most common pod car seats two people in an inline configuration, not side-by-side. It would also be possible to build pods seating more people or vehicles for only one person. Pods are capable of either manual or autonomous operation. In autonomous mode, the occupants have no control of the pod after the destination has been selected.

Guideways for the pod cars are converted freeway lanes. A lane is removed from general use and barricaded and gated so that only automated pods may enter. Each old lane is split into two half-wide pod car lanes. Because of reduced following distance each new lane has more capacity than an old lane. The magnitude of this capacity increase is not know, but a conservative estimate would be a $50 \%$ increase. Two half wide lanes may be able to carry as many vehicles as three non-automated full width lanes. Thus replacing three old lanes with two half-wide automated lanes and two regular lanes could carry the traffic of five ordinary lanes. If the automated lanes are heavily used, non-automated vehicles will experience less congestion despite having lost a lane. 
A required modification to infrastructure would be entry ramps that would read an electronic credential and verify suitability to operate on the automatic system. An unsuitable vehicle attempting to place itself under automated control is instead routed into a non-automated lane. A vehicle attempting to operate manually in an automated lane could be prevented by a physical barrier or automatically given a traffic violation. Vehicles are tested to earn their electronic credentials. This test could enforce limits on size, weight and fuel efficiency. A fuel efficiency standard could be set by a municipality and might be more stringent than the national limit. If an owner tampers with the vehicle and it fails to perform properly in the system, the credential is revoked. A fine or other penalty could be assessed against the owner.

Minimum vehicle capabilities to operate automatically must be standardized. The standards must specify vehicle to infrastructure and vehicle to vehicle communication frequencies and protocols. The protocol may make use of an encrypted vehicle identification number.

Of course it is also possible to construct new guideways for the pod cars. These could be elevated, underground or in freeway right-of-way. The guideways could be light and follow the construction techniques suggested for PRT. Pod car ownership can be public, such as PRT, or private personal transportation. If the pods are personal vehicles, they are purchased or leased by individuals, removing the need for taxation to purchase vehicles.

The standard pod car holds two people. If additional capacity is needed for goods or additional passengers, two or three pod cars could be electronically linked, where the extra vehicles must follow the leader. A group finding this arrangement inconvenient can take a car or bus. Pod cars are not meant to be all things to all people. They may not be suitable for rural trips.

\subsection{Vehicle and Traffic Control}

Many of the autonomous vehicles that have been demonstrated to date make use of expensive sensor systems, such as radar or LIDAR. There are less expensive ways to keep a vehicle in lane. One option is a camera that can recognize painted lane markers or other lane boundaries in real-time. Ultrasound or laser range finders can judge the distance to a curb or other lane-side barrier. When the barrier contains coded and mapped indentations, it can also assist in vehicle navigation.

Vehicle to vehicle communication will give a pod car awareness of which vehicle is in front of it. It can know that vehicle's position, speed and acceleration as well as any planned changes to velocity or trajectory in the next several seconds. The system is designed to eliminate unexpected occurrences. Pedestrians and non-automated vehicles are prohibited in the automated lane.

It is not practical to prevent all unexpected events such as debris, snow, ice, tire blowouts or other mechanical failures. Vehicles must have sensors adequate to detect and respond to these situations. Alternatively, a standardized physical coupling system might be required in a platoon.

Once a vehicle is capable of autonomously operating itself, sensing its environment and location, it can be placed under the control of a supervisory traffic control computer. Intelligent Transportation Systems (ITS) are then transformed from posting driver advisories to taking control of the vehicles. An ITS system could be centralized, as it often is. Alternatively, ITS could be a distributed system, where a traffic control computer handles the vehicles near a particular interchange and passes vehicle control to the next sector as vehicles exit. It is also possible that no ITS computer is needed and that intelligent traffic control will emerge as the behaviour of the interactions of autonomous vehicles [13].

The goal of ITS on the half-wide automated lanes is to keep all pod cars moving at the system design speed all the time. There must be sufficiently large buffers at exits to prevent backups. A pod car entering the system must know where gaps are located in the traffic stream and time its merge precisely so that it does not cause other vehicles to slow. This capability has been demonstrated with autonomous vehicles [14]. If the system saturates, new vehicles will be prohibited from entering but all vehicles already in the lane will move at full speed. All interchanges must have sufficiently large holding areas so vehicles can merge into the traffic stream without slowing any traffic.

\subsection{Design Summary}

Further automation of transportation is inevitable. We will see improved methods for operating individual vehicle and coordinating motions of vehicle swarms. Automobiles are likely to incorporate intelligent cruise control, collision avoidance systems, lane-following systems and automatic parking [15]. These systems have been demonstrated and will likely find their way into the market whether or not the systems are coordinated.

The proposed automated pod car is a new transportation mode. It is not an automobile, motorcycle, bicycle, train or bus. Its size is between a motorcycle and a car. It can perform the people moving functions presently handled by cars, buses and commuter trains. At present, $88 \%$ of Americans use a car, van or light truck to get to work, with the vast majority driving alone. Only $4 \%$ depend on public transit to get to work [16]. The pod car could provide urban drivers with inducements to leave the car in the garage. Pod cars could be faster, safer, more convenient, less expensive and more sustainable than the automobile. There are situations where cars or light trucks are effective and we do not seek to design a vehicle that does everything.

To reiterate, the requirements for an urban people mover are to provide a transportation system that improves on the automobile in

- Total time of trip.

- Convenience. 
- Cost.

- Safety.

- $\quad$ Energy and resource consumption.

These requirements apply to the total system, not just the vehicles. The suggestions above represent one design to meet the requirements. There are other designs that accomplish the same objectives.

\section{Experimental Vehicles}

The potential benefits of autonomous vehicles are clear. The remainder of this paper is concerned with how to build a low cost light autonomous land vehicle. We next discuss several vehicles that the author's research teams have developed and the lessons learned from each.

\subsection{Sleipnir}

Sleipnir is named for Odin's magic horse in Norse mythology. Team Sleipnir worked on an automated vehicle from November 2004 to July of 2005. The vehicle, shown in Figure 3, was intended to travel autonomously on dirt roads and was an entry in the DARPA Grand Challenge. Sleipnir was a modified Kawasaki all terrain vehicle (ATV). The design emphasized meeting the needs that caused DARPA to hold the contest. The system was built using the relatively simple sensors of camera and GPS. Obstacle detection was to be performed by stereo camera vision. There was no use of LIDAR, radar or other expensive and delicate ranging instruments. Stereo vision was achieved from a single camera using mirrors [17, 18]. This avoided the need to keep two cameras in adjustment and aligned. Instead of using standard algorithms, stereo vision relied on primitive image transformations performed in the human retina and primary visual cortex [19].

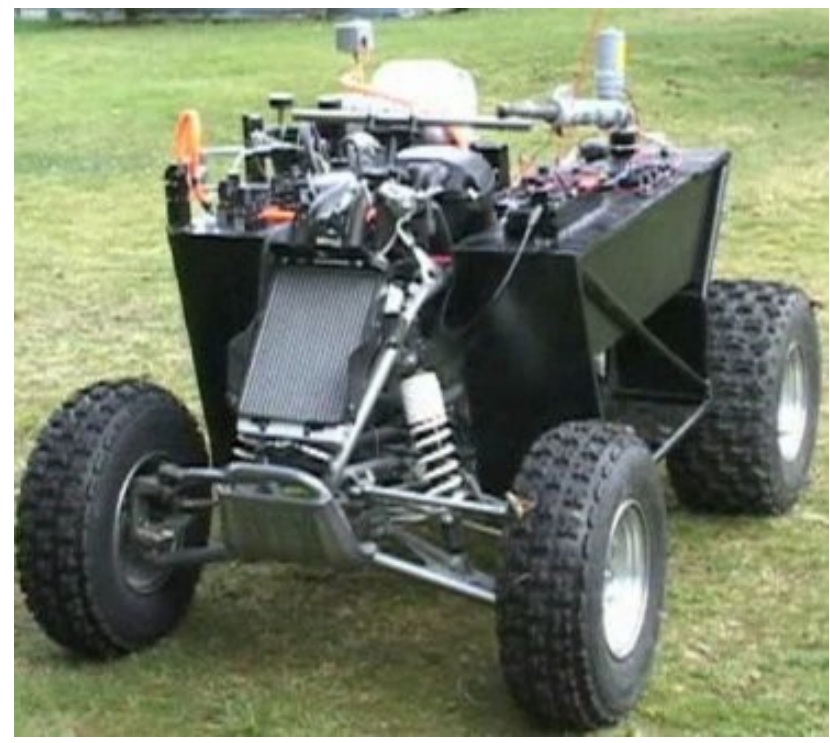

Figure 3: Sleipnir
Unlike most Grand Challenge entries, Sleipnir's control system was not based on a PC. Instead it used a stack of Digital Signal Processors (DSP) as is the case with much military equipment. Sleipnir was two-wheel drive, but had a power to weight ratio higher than any other contest entry. It included pneumatic systems for steering control and emergency stop.

Participation in the DARPA Grand Challenge had multiple milestones, and teams failing to qualify were dropped. The government required teams to file a technical report some months after the initial registration. Later it required a video showing that the vehicle was capable of performing certain actions. Teams with accepted videos were then visited at their site by DARPA inspectors who observed the vehicle in action. Those who passed the site visit came to the qualifying event at a California race track a few months later. About 20 of the hundreds of applicant vehicles were allowed to participate in the race from Barstow CA to Primm NV.

Sleipnir performed well under Radio Control. The team made a successful video. Days before the site visit, it became clear that the vehicle was not capable of operating under computer control.

Lessons learned:

- Mechanical systems were well done, but most of an autonomous vehicle is software.

- Good software management with milestones is needed.

- More software was needed than two full-time professionals could provide.

- Using a state-of-the-art DSP was overly ambitious, since many sensors and actuators only have drivers for PCs.

- A DSP uses less power than a PC, but it is not clear that its architecture overcomes its lower clock rate. A PC may have been able to provide higher performance.

- Mirrors can be used to achieve stereo on a single camera, but alignment is critical. A commercial stereo vision system may be more robust.

- The biologically based stereo system was complex and never performed satisfactorily.

- Stereo vision has limited range and may not be sufficient for obstacle detection.

- Sebastian Thun of Stanford won the race by using a range sensor to adaptively interpret a monocular image. This extended the sensor range beyond what LIDAR could supply [20]. Stereo cameras may be usable in the same way to infer range information from a single camera.

\subsection{Snow Storm}

The vehicle that many people expected to win the first DARPA Grand Challenge race in 2004 was CarnegieMellon University's "Sand Storm". The University of British Columbia (UBC) named their entry in the 2005 
race "Snow Storm" in keeping with the stereotype of snow in Canada. Snow Storm (Figure 4) was also entered in the 2007 DARPA Urban Challenge and this section concerns that effort.

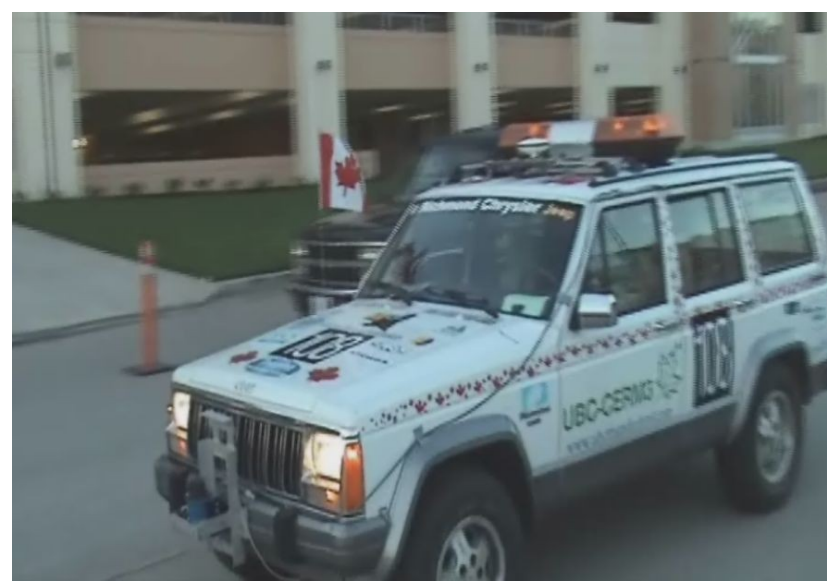

Figure 4: Snow Storm

Following the 2005 Grand Challenge race across the desert, DARPA held another race in November 2007 called the Urban Challenge. Unlike the two previous Grand Challenge races, it tested the ability of autonomous vehicles to drive in traffic. The event was held on an abandoned military base and 50 race car drivers were hired to drive traffic vehicles. In the desert races, the route was not know until the day of the race and even then was not specified in detail. For the Urban Challenge, detailed digital maps, called the Route Network Definition File (RNDF) were available in advance [21]. The Mission Definition File (MDF) consisted of required waypoints and was presented to a team five minutes before departure.

The UBC team consisted entirely of volunteers, mostly undergraduate students. None of the students received academic credit for participation. Work parties were normally held once per week. Snow Storm was an old Jeep Cherokee with a computer controlling the steering, throttle and brakes. The sensors included GPS, Inertial Navigation Unit (INU), odometer, stereo cameras and a Ibeo automotive LIDAR scanner. One of our volunteers was a professional game programmer who contributed a great deal of evening and weekend time. He also made his personal game engine, designed for auto racing games, available to the project. That system combined vehicle control, simulation and data recording. This meant that when the vehicle behaved anomalously, it was possible to replay the situation and use a source code debugger to identify how the computer code had misbehaved. The disadvantage of the system was that it was complex and undocumented, making access by other software engineers difficult.

The team also identified the USARSIM simulator [22]. It was originally written to support NIST efforts in robotic urban search and rescue but has been generalized to support a wide range of robots, including robotic highway vehicles. The simulator is a modification to a commercial game, but is otherwise open source and well documented. We were able to modify the code to support simulation of the DARPA Urban Challenge. There is also a related open source robot controller [MOAST] but this proved more difficult to use [23].

A drive-by-wire game steering wheel and throttle/brake was provided on Snow Storm's passenger side. These systems could be selectively placed under autonomous or manual control. In the DARPA events, no passenger rides in the vehicle, but it is followed by a chase car that can activate an emergency stop.

Safety was always a high priority and the vehicle was never operated without a working E-stop. The team was able to achieve autonomous operation. The first stage of autonomy was to follow a set course given by GPS coordinates. We were also able to detect lane markers in real-time. The intent was to integrate lane following camera information, odometry, RNDF map and GPS into a localization system, but that work was not completed.

Detection and avoidance of dynamic and static obstacles was achieved by a commercial system manufactured by Ibeo Automotive Systems [24]. The compact unit uses a triangular plane of LIDAR approximately parallel with the pavement to detect the ranges of objects. Four planes over tightly spaced angles are used to allow for the pitch of the platform. The system includes software to group the signals into representations of vehicles and reports them as static, car, truck, bicycle or pedestrian and gives speeds. The retail price of the system is over 12,000 euros, but Ibeo projected that the price could decline to a few hundred euros in a mass market [25].

When DARPA officials arrived for the site visit, localization was by GPS alone. The site selected for this trial was GPS friendly: a raceway on flat land with no buildings and no trees near the track. The vehicle was able to travel autonomously around a 200 meter loop. The GPS system used had a specified accuracy of $1 \mathrm{~m}$. However, the accumulated error by the end of the loop was equivalent to the width of a street. The vehicle was required to stop at a stop sign of a simulated intersection. Due to the GPS error, Snow Storm had crossed the intersection before reaching what it thought was the GPS position of the stop sign. The car thus failed the site visit and did not participate in the semifinals.

The student team was not able to robustly integrate the Ibeo obstacle avoidance system into Snow Storm's control system. The Ibeo company did enter its own car into the DARPA Urban Challenge. That vehicle used three Ibeo sensors and was able to pass the site visit. In the semifinals it had difficulty recognizing all obstacles and did not qualify for the final race.

Lessons learned:

- Autonomy was achieved by volunteers working part time on a small budget.

- GPS alone is not sufficiently accurate to localize an autonomous vehicle. 
- A combination of good digital maps, lane following camera, odometer and compass would be sufficient for localization.

- Odometer drifts can be eliminated by GPS or fixes on landmarks.

- Taking proper actions to avoid other vehicles is considerably more complicated than following a set course.

- Commercial systems to recognize dynamic and static obstacles, avoid collisions and stay in lane are available. Their price is likely to fall drastically as a mass market develops.

- Integration of vehicle control, data logging and simulation in a single system can be useful.

- A complex but undocumented software system may only be usable by its author.

- An open-source robot simulator (USARSIM) is available that models autonomous road vehicles and their sensors. It can be resource hungry, but performs well in real-time. It is well documented and has an active user community.

- An open-source robot controller (MOAST) is also available, but is more difficult to use.

\subsection{Cheater}

Cheater, shown in Figure 5, is a manually driven vehicle that tests how small, light and inexpensive a pod car can be. The vehicle cheats the wind and does not properly fall into a category for bicycle, scooter, car, or Electrathon racer. The chassis is a Catrike Road recumbent tricycle [26]. It has an electric assist unit from BionX that consists of a $350 \mathrm{~W}$ rear hub motor, a Lithium-Ion battery and a controller [27]. The BionX system is designed to provide electrical assist for pedalling.

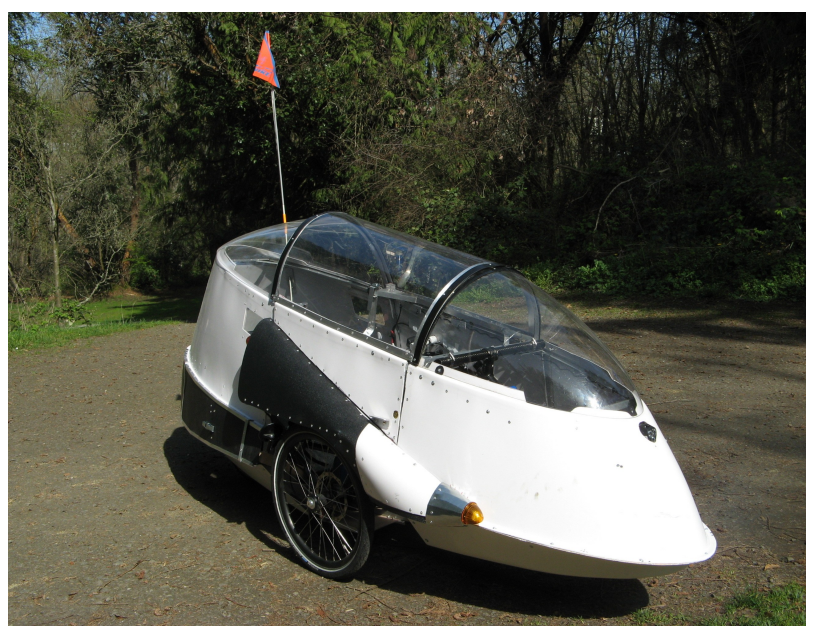

Figure 5: Cheater

Cheater is fitted with a weather-proof body [28]. The body consists of three parts:

1. A clear canopy of acrylic and lexan.

2. The middle body portion is made of ABS plastic
3. The belly pan is made of fibreglass.

The body is riveted to a framework of aluminium that attaches to the chassis.Cheater is a hybrid of human and plug-in electric power. There are commercial manufacturers of similar human powered vehicles (HPV). Many of the available vehicles were judged to lack practicality. A custom vehicle was built to allow for ease of entry and provide cargo capacity for five sacks of groceries.

The vehicle measures $0.78 \mathrm{~m}$ wide, $1.09 \mathrm{~m}$ high, $2.59 \mathrm{~m}$ long and weighs $48 \mathrm{~kg}$.

Lessons learned:

- A significant effort is involved in adapting a fairing to a chassis. A stock HPV is a good value if it meets your needs.

- Typical city streets are rough and have too many potholes. They limit the top speed for a vehicle without suspension to under $30 \mathrm{kph}$.

- A vehicle designed for $50 \mathrm{kph}$ should have motorcycle grade suspension and wheels.

- The fairing must allow easy access to the wheels for maintenance. Otherwise a flat tire becomes a major repair.

- On smooth pavement with a bit of a down-slope the aerodynamics of Cheater make it faster than a conventional bicycle.

- Without electric assist, the vehicle climbs hills much more slowly than an upright bicycle.

- On level roads the vehicle seems to become more efficient than a normal bicycle only at speeds above $30 \mathrm{kph}$. The equations predict that this crossover point should be about $20 \mathrm{kph}$ [11].

- The canopy is effective in keeping the rider dry in wet weather, though there is also a need for fenders to guard against water on the road.

- Visibility can go to near zero from rain drops and fogging. Proper ventilation is important.

- A large clear canopy can quickly make a closed vehicle unbearably hot in sunny weather.

- The shell and chassis provides some crash protection to the rider and a seat-belt should be worn.

- There needs to be an emergency exit if the vehicle lands on its side.

- The low profile and silence means that the vehicle may not be noticed by cars. Visibility is increased by a flag, lights and eye-catching design. A good horn is required.

- A cruising range of $50 \mathrm{~km}$ is possible from a 3.7 $\mathrm{kg}$ battery when assisted by pedalling

- A somewhat larger motor and battery will be needed to maintain $50 \mathrm{kph}$ without pedal assist.

- Uphill starting requires significant power. 


\subsection{Electrathon}

Electrathon is a one hour race that tests how far an electric vehicle can go using only two standard car batteries [29]. The events are usually held on a race track or other closed loop, as in Figure 6. Participants are teams of high school students, college students or hobbyists. Winners may cover 65 to $80 \mathrm{~km}$ in an hour. The world record is $100 \mathrm{~km}$ (62 mi) in one hour. This was set on July 20, 2009 at Ford's Michigan Proving Grounds by a vehicle using 950 watts $(1.3 \mathrm{hp})$ of power from conventional lead acid batteries. Energy efficiency was $9.5 \mathrm{~W} \mathrm{hr} / \mathrm{km}$ or 0.11 $1 / 100 \mathrm{~km}(2200 \mathrm{mpg})$ equivalent at freeway speed. [30]

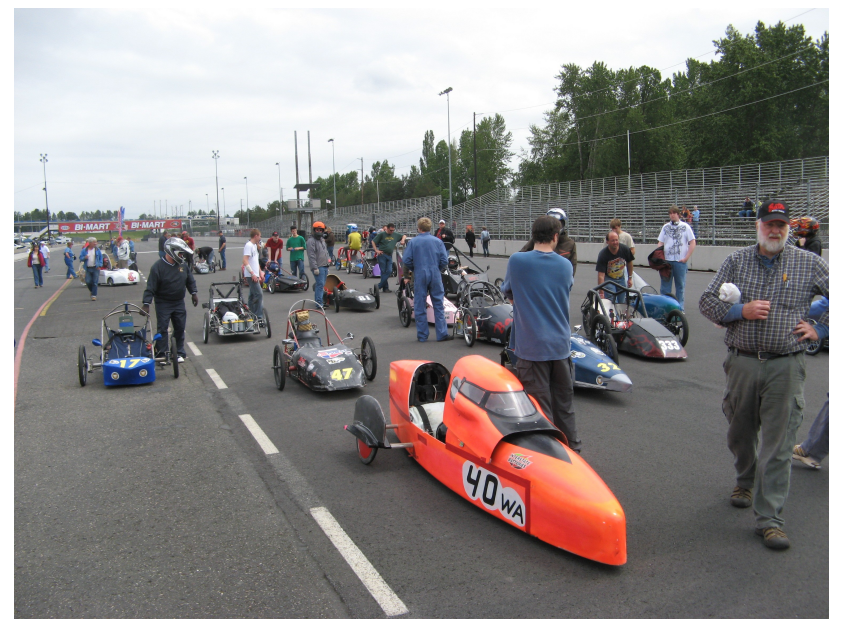

Figure 6: Electrathon

Lessons learned:

- Building a light electric vehicle is a technology accessible to students and hobbyists.

- Very high fuel efficiency is possible.

\section{The Elcano Project}

Autonomous vehicles are not rocket science. The Seattle Robotics Society sponsors a Robo-Magellan event, which is a version of the DARPA Grand Challenge scaled down to be accessible to hobbyists [31]. The contest limits robot weight to $23 \mathrm{~kg}(50 \mathrm{lb})$; size is restricted so that the vehicle must fit inside a cube $1.1 \mathrm{~m}(4 \mathrm{ft})$ on an edge.

It is our contention that autonomous vehicles can be constructed inexpensively, making them accessible to high school and college teams that compete in events such as Electrathon. Such an educational effort would increase awareness of the proposed transportation concept and help to train and motivate the engineers who can make it happen.

We have thus embarked on an open source hardware and software project to spread awareness of the concepts. The first step is the Elcano project to build the ultimate RoboMagellan vehicle, shown in Figure 7 [32]. Magellan was killed in the Philippines. The first people to circumnavigate the globe were 18 survivors of Magellan's fleet, under the command of Juan Sebastian Elcano.

Since the hardware and software for the Elcano vehicle will be publicly available, we expect performance in Robo-Magellan events to quickly improve. The vehicles may start to look like driverless Electrathon vehicles.

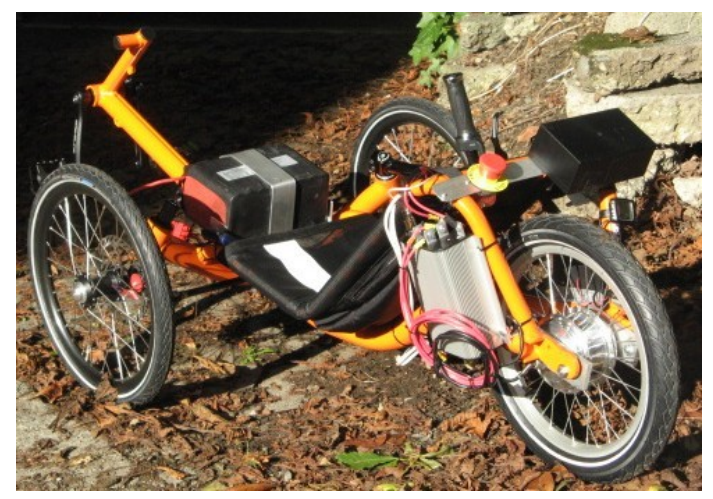

Figure 7: Elcano

Once it has been demonstrated that capable autonomous electric vehicles can be routinely constructed, the next stage is an open source effort to perform clustering.

The open source vehicles will not be safe enough to form a transportation system. Rather, the initial effort is a proof-of-concept. Once the system has captured the public imagination, a private company or national government can be expected to make an investment in the technology to bring the system to market. This requires high reliability, which can be achieved by formal methods [33]. The operational software would need to meet standards similar to avionics software. The necessity for rigorous testing and certification can give a private company Intellectual Property that is a basis for a profitable business despite the public proof-of-concept.

Elcano's chassis is a Catrike Dash recumbent tricycle [34]. The chain, derailleur, and sprockets have been removed. The rear wheel has been replaced by a wheel built on a hub motor, which was designed to be used as a front wheel. The hub motor is powered by a lithium battery run by a Kelly controller. Brakes and steering will be placed under computer control.

Computer power comes from a stack of Arduino microcontrollers [35]. This is a standard mobile robot architecture [36] and has some similarity with a modern automobile, which uses dozens of microprocessors. It is not planned to use an operating system or personal computer. The firmware is distributed on several machines to improve reliability and security. Small software programs are suitable for formal methods and in some cases can be proven correct [37]. Each module in the software architecture is hosted on its own microcontroller. The modules are:

- Motor Controller: Receives a command from the Pilot specifying rate of wheel rotation and steering angle. It controls the actuators to the traction motor, brakes and steering to make it happen. 
- Pilot: Outputs the specific instantaneous motion. It receives the desired route for the next segment as a Bezier or Hermite cubic curve [38] specifying the path and a desired speed profile.

- $\quad$ Path Planner: Uses RNDF and MDF digital maps and receives location and velocity information from the Navigator. It feeds the desired route section by section to the Pilot.

- Navigator: Fuses information from sensors including wheel odometry, visual odometry, wheel angle, compass, digital map, commanded speed and steering, and GPS. It passes location information to the Path Planner.

- $\quad$ Obstacle avoidance: Receives information from a smart camera and modifies the planned route as needed. It uses camera information to stay in lane.

Image processing is the largest computational task and requires a more powerful machine than the Arduino. Instead of programming this task, we plan to buy a smart camera that is able to process visual information and extract key features. Several such systems have been prototyped.

The system is compatible with the USARSIM simulator when the vehicle and Motor Controller module are omitted. More details of the Elcano design can be found online [32].

\section{Conclusion}

The technology for a PRT system is at hand. Automated cars and highways have been demonstrated. More experience is being accumulated with autonomous land vehicles. These technologies are converging and offer a chance to change transportation. The benefits most often cited are improved safety and reduced congestion. This change in transportation gives an opportunity to break with business as usual and invent a new transportation paradigm, where moving people is more important than moving vehicles.

The change in technology could be accompanied by a severe reduction in vehicle weight and energy consumption. The new transportation mode would be sustainable and could achieve fuel efficiencies in the range of 0.50 to $0.251 / 100 \mathrm{~km}$ (500 to $1000 \mathrm{mpg}$ ) equivalent. A key piece of the puzzle is to demonstrate that a basic vehicle for this system can be built for under $\$ 10,000$.

The model to demonstrate proof of concept does not depend on government funding, venture capitalists or investors. We propose an open source, grass roots effort that cannot be stifled by vested corporate interests. When the technological path becomes clear, the time will be ripe for a corporation or national government to commercialize the system. Please help to redirect advances in automatic vehicles and infrastructure toward sustainability.

\section{References}

[1] http://www.advancedtransit.net/atrawiki/index.php?title= Personal Rapid Transit.

[2] NAHSC,1998, NAHSC Technical Feasibility Demonstration Summary, Troy, MI.

[3] http://www.path.berkeley.edu/Videos/movie24.html.

[4] S.E.Shladover, Automated Driving: Real-World Feasibility and Benefits, 90th meeting of the Transportation Research Board, Jan 26, 2011.

[5] http://news.bbc.co.uk/2/hi/8349923.stm

[6] U.S. Dept of Labor, Bureau of Labor Statistics, www.bls.gov/cex/2007/standard/income.pdf, Oct. 2008.

[7] S.Rabuel, Les transports publics guidés en France : Données 2005 - métropole hors Paris/Île-de-France.

[8] L. D. Shen, J. Huang and F. Zhao, Automated People Mover Applications: A Worldwide Review, 1995

[9] D. Hakim, Average U.S. car is tipping scales at 4,000 pounds, NY Times, May 5, 2004.

[10] Advance Data from Vital and Health Statistics, No. 347, Oct 2004.

[11] D. G. Wilson, Bicycling Science, Cambridge, MA, 2004

[12] https://www.media.volvocars.com/global/enhanced/en$\mathrm{gb} /$ Media/Preview.aspx?mediaid $=36000$

[13] M. Materic., "Behavior-Based Control: Main Properties and Implications", IEEE International Conference on Robotics and Automation, Nice, France, 1992.

[14] S.Tsugawa, Automated Driving: Real-World Feasibility and Benefits, 90th Transportation Research Board, Jan, 2011.

[15] R. Bishop, "The Thinking Car", Vehicle-Highway Automation, 90th Transportation Research Board, Jan, 2011.

[16] www.census.gov/population/www/socdemo/journey. html

[17] S. Baker and S.K. Nayar, A Theory of Single-Viewpoint Catadioptic Image Formation, International Journal of Computer Vision, 35(2):175-196, 1999.

[18] J. Glukman and S. K. Nayar, Rectified Catadioptic Stereo Sensors, IEEE Transactions PAMI, 24(2):224-236, 2002.

[19] T.C. Folsom, "Non-pixel Robot Stereo", IEEE Symposium on Computational Intelligence in Image and Signal Processing, Honolulu, HI, April 2007.

[20] S. Thun, Winning the DARPA Grand Challenge, IEEE World Congress Computational Intelligence, Vancouver, 2006.

[21] http://www.darpa.mil/grandchallenge/docs/RNDF_MDF_ Formats_031407.pdf

[22] http://sourceforge.net/projects/usarsim/

[23] http://sourceforge.net/projects/moast/

[24] http://www.ibeo-as.com/

[25] Personal communication.

[26] http://www.catrike.com/catrike_road.html

[27] www.bionx.ca

[28] http://www.blueskydsn.com/products.html

[29] www.electrathonamerica.org

[30] http://www.electrathonamerica.org/News.html

[31] http://www.robothon.org/robothon/robo-magellan.php

[32] http://sourceforge.net/projects/urbanchallenge/

[33] J. Jacky, The Way of Z, Cambridge, 1997.

[34] http://www.catrike.com/catrike_dash.html

[35] http://www.arduino.cc/

[36] R.R. Murphy, Introduction to AI Robotics, MIT Press, 2000.

[37] I. Sommerville, Software Engineering, Pearson, 2004.

[38] J.D Foley et al. Introduction to Computer Graphics, Pearson, 2004. 